\title{
Drafting the Discourse Structures of the Graduate School Academic Colloquium
}

\author{
Joan C. Ravago ${ }^{1}{ }^{*}$, Gina O. Gonong ${ }^{2}$, Joel M. Torres ${ }^{3}$ \\ ${ }^{1}$ Department of English and Humanities, College of Arts and Social Sciences, Central Luzon State University, \\ Science City of Muñoz 3119, Nueva Ecija, Philippines \\ ${ }^{2}$ Philippine Normal University, Manila, Philippines \\ ${ }^{3}$ Department of Secondary Education, College of Education, Central Luzon State University, Science City of \\ Muñoz 3119, Nueva Ecija, Philippines
}

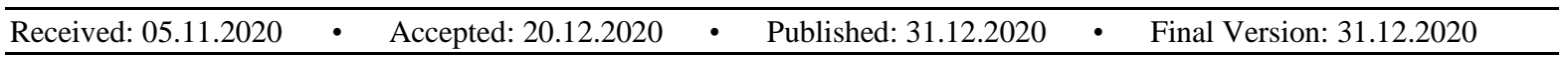

\begin{abstract}
Using the data transcriptions from the communicative events obtained from four participating universities, 33 graduate students, and 26 panel of experts, this paper examines several colloquium events in the Philippines to identify any existing "global" structure of discourse categorized into semantic and schematic superstructures (van Dijk, 1980). Results show that the semantic macrostructure of a colloquium is reflective of its collective goal, and that the participants focus on the improvement of graduate students' paper. In addition, the discourse of the colloquium has a stable schematic superstructure that is always followed in realizing the collaborative end of the colloquium. Each phase consists of both obligatory and optional features that define/reflect the institution's identity and practice. Understanding these structures may help candidates of graduate school degrees surpass the challenging task of writing theses and dissertations with an advantage.
\end{abstract}

Keywords: discourse analysis, academic colloquium, semantic macrostructure, schematic, superstructure

\section{Introduction}

The interest of scholars in studying the ways how human beings use language and its properties in communicating intentions and maintaining social relationship among the members of the community-through utterances, conversation, talk, and the more technical and broader term, discourse- is evident on the increasing number of studies and endeavors that have emerged and continue to emerge across disciplines such as humanities, social sciences, history, literature, and political science. Barron (2003 in Torres, 2020) provided a comprehensive definition of the concept pragmatic competence as the knowledge of the available linguistic resources in a language for the realization of some illocutions, knowledge of speech acts' sequential aspects and contextual use of a language's linguistic resources. This interest has led to a new method of investigation, discourse analysis, to fully understand and describe the nature and properties of discourse in relation to other linguistic and social components. Discourse analysis, then, is defined as not only a linguistic analysis of text but also an analysis of the order of discourse including structuring and networking of social practices (Fairclough, 2003). It is based on the details of speech (and gaze and gesture and action) or writing that are arguably deemed relevant in the situation and that are relevant to the arguments that analyst is attempting to make (Gee,1999, p. 86).

\footnotetext{
* Corresponding Author: joan@ clsu.edu.ph
} 
One of the genres that is slowly gaining the attention of scholars and discourse analysts is academic discourse, a type of discourse that is done in the academy or in other school situations. It involves a special kind of vocabulary, norms, and conventions intrinsic to academia and more specifically, an integral part of the individual disciplines therein (Zamel, 1998). Topics of analysis range from socializations (Ariff \& Mugableh, 2013), self-mention and multiple identities (Zareva 2013), lexical composition (Zareva 2012), linking adverbials (Zareva 2011), university office hour interactions (Limberg, 2007), non-comprehension in graduate seminars (Waring, 2002), university lectures (Young, 1994; Bamford, 2000), and face concerns and attributions in intellectual discussions (Tracy \& Baratz, 1993) to name a few. Among the vast range of subjects under this genre, colloquium/intellectual discussion/defense, as well as its actual characteristics, receives little attention from the scholars (Yang, 2014; Chen, 2012; Duff, 2010; Swales as quoted by Recski, 2005; Hartley, 2000; Burling, 1997; Grimshaw \& Burke, 1994; Grimshaw, 1989).

Colloquium as an intellectual discourse is a part of the academic requirements of the graduate students before finishing their degree. It is the stage of thesis/dissertation defense that requires them to present the first three chapters of their paper to a panel of experts to challenge and question the proposed concepts in the paper and to give feedback and modifications at the end. The presenter's major concern is to express his/her view and to persuade the audience of the relevance and value of his/her study (Querol-Julian, 2010). As Tracy and Baratz (1993) observe, it is a form of intellectual discussion in an institutional setting that provides a dilemmatic situation for its participants, the faculty and graduate students. These authors argue that it is dilemmatic for the faculty because they must put forward their suggestions without offending the researcher and the other members of the panel who have different ideas from them. It is also dilemmatic for the researcher because he or she must humbly accept the suggestions of the panel even if that means he or she must revise his or her paper totally. Also, the researcher must defend his or her position without being too pushy or disrespectful to the panel.

Given the relevance of this discourse type in the academic setting particularly among the graduate students, a study that focuses on how the discourse unfolds and how communicative goals are achieved is deemed imperative. This paper draws from the idea that establishing the discourse structures of a colloquium conducted in a graduate school colloquium can inform and prepare the graduate students on the intellectual discourse, thus, help them to successfully pass this academic phase.

\section{Literature review}

\subsection{Colloquium}

The nature and procedure of colloquium vary according to context. In fact, as findings of previous studied revealed, its participants could range from 10-25 participants (Tracy \& Baratz, 1993), 3-5 (Maingueneau, 2002), and 50 in Scandinavian context (Recski, 2005). Panelists likewise varyexternal and internal member who conducts the ceremonial, senior university official (Recski, 2005), and the most influential part of the academic community (Maingueneau, 2002).

As regards colloquium procedure, the meeting opens with a presentation by the candidate, followed by interactions between the candidate and each member of the jury, at times between members of the jury; only the audience is excluded from the interaction. After these ceremonies, an RTDM (Report on Thesis Defence Meeting) is written to evaluate the thesis and the performance of the candidate during the defense meeting (Maingueneau, 2002). On the other hand, Weissberg (1993) 
revealed this structure: the presiding professor introduces the student's academic advisor, the academic advisor introduces the student speaker, the student presents the seminar, accompanied by slides, and questions are taken. In closing, these studies suggest that a colloquium or any oral defense in its broad sense, follows different patterns of proceedings, participants and their roles, and length.

\subsection{Discourse structure}

The structure of discourse, with its wide range of scope, is as complex and diverse as what has been presented on the paragraphs above. To begin with, such complexity is evident on how the different authors term it: discourse structure (Teufel, 2012); discourse organization (Biber, Connor, \& Upton 2007); and rhetorical organizational pattern (Swales, 1981 in Biber, Connor, Upton \& Kanoksilapatham 2007). Equally complex as its term are its definition, description, and analysis. To illustrate, it is "the organization of language above the sentence" (Teufel, 2012) or the linguistic structure beyond the sentence (Biber, Connor, \& Upton, 2007). From the perspectives of genre theory, such as Swales' (1981) move analysis, a discourse has conventionalized structure or standard structure with default elements identified equivalent to van Dijk's (1988) superstructure (Berzlánovich, Egg, \& Redeker, 2012). Summing these up, one must follow a guide in inferring the hierarchical structure of discourse: it must be guided by the relations between information in the discourse and the intentions of the users (Denecke, 1999).

\subsection{Semantic and schematic discourse structure}

As for the different description of discourse structure, and in which this paper is anchored on, van Dijk (1980) proposes a global structure of discourse categorized into semantic macrostructure and schematic superstructure.

The semantic macrostructure of discourse pertains to the global meaning of the discourse that includes the notion of gist, summary, and topic (van Dijk 1980). Seidlhofer (1995) provides a more simplified version of Kintsch and van Dijk's (1978) concept on how to deduce this macrostructure (used interchangeably with semantic macrostructure). This simplification, with some of our inferences, explains that each discourse consists of propositions (sentences). This sequence of sentences is reduced and organized into macropropositions or the intermediate semantic structures that are just underneath the main themes of the text (Neubert \& Shreve, 1992). In short, these macropropositions are the simplified meaning of the sequence of utterances in each discourse. Getting the macroproposition can be inferred as the initial level of deriving the semantic macrostructure of the text, that is, the same process of macrorules (deletion, generalization, and reconstruction) can be applied again and again until finally one can organize a higher level of global meaning or the sentence-length semantic macrostructure or the over-all meaning of the text (Seidlhofer, 1995).

On the other hand, schematic superstructure, pertains to the global form of discourse which involves the concepts of outline, introduction among others (van Dijk, 1980). This structure reflects features of conventional text types such as stories or psychological reports (Seidlhofer, 1995). As van Dijk and Kintsch (1978 in Seidlhofer, 1995) explain, highly conventional text types specify the schematic structures of the text such as (a) a pastoral letter has these sections: - establishing authority, contextualizing the need to write the letter, declaring the stand of the organization, i.e. CBCP, instructing courses of actions to do, and praying for providence (Gochuico, Gonong, \& Reyes 2015); (b) State of the Nation Address (SONA) has introduction (acknowledgment of audience, attention getter statement, introductory statements), body- the transition (reference to previous events and circumstances, to a known great event, to history and to previous SONA) and the main points (report 
of accomplishments and discussion of agenda- statement, explanation, and proposed action), and conclusion- (summary), (memorable statement), appeal for unity and action, and (imploring God's help)) (Gonong, 2007); and (c) travel advisory has warning-justification-reiteration structural pattern (Alcoberes, 2010). In this sense, the relationship that exists between the semantic macrostructure and schematic superstructure can be described as slot and filler (Seidlhofer, 1995) where the former is the schematic superstructure and the latter, the semantic macrostructure. Finally, El Sakran and Adamson (2019) express that it is generally agreed that the more conventional a genre is- that is, the more constrained its communicative purposes are- the more predictable will be its schematic structure.

The semantic macrostructure of a discourse as an object of study has been dealt greatly in critical discourse analysis of political speeches and news reports. Although the discourse genres and the researchers differ, it was found that there was a shared method of analysis in abstracting the semantic macrostructure of discourse: reading the text, inferring the macropropositions, forming the over-all macroproposition or the higher level macropropositions, and finally producing the semantic macrostructure (Al-Saaid, Pandian \& Al-Shaibani, 2016; Qomaruddin, 2015; Al-Shaibani, 2014).

Our research inquires about the discourse structure of the colloquium in terms of its semantic macrostructure and schematic superstructure, and their possible implications in the advancement of post-graduate students' success.Information about references

\section{Materials and Methods}

\subsection{Research Design}

This study is a qualitative-case study design. This is incongruence with what Phipps and Borg (2009 in Torres, 2013) mentioned that qualitative methods are helpful in advancing our understanding of the complex relationships among phenomena. A case study, which allows in-depth analysis of the participants' practices prior to considering the findings collectively (Torres, 2012), comprehensively investigates a single participant or group of individuals employing several methods like unstructured interview and observation and is used in qualitative-based data (McLeod 2008). Similarly, Interactional Sociolinguistics (IS) is an approach that makes use of actual utterances of participants in an interaction such as colloquium. In our application, IS focuses on the verbal and non-verbal language, paralinguistic markers, and cultural factors in analyzing how these participants in the colloquium construct and negotiate meaning. It is evident therefore that the derived data from this approach are best understood, explained, and interpreted through qualitative discussion, and our thoughtful reflections and analysis (Berkwits \& Inui, 1998). As Kothoff (1996) states, understanding how the participants reconstruct meanings requires a qualitative approach.

\subsection{Participants}

Two groups of participants, the graduate students (two doctoral students, five master's), and the panel of experts (including the adviser and the chair) comprised this study. The study did not consider only the graduate student presenter since colloquium as a communicative event requires the presence of panel of experts who also makes contribution to the discourse. These participants came from four different universities in the Philippines which were purposively selected. We considered the program offerings that belong to our discourse community, such as behavioural sciences and social sciences, and the context of colloquium, that is, a graduate student presents the first three chapters of his/her 
study to a panel of experts because there are some universities in the Philippines which require the presentation of only the first two chapters.

All the participants were coded to protect their anonymity (Torres \& Flores, 2017). The code was a combination of a letter and a number. The letter code was based on their role in the colloquium, GS (graduate student, A (adviser), P (panellist), whereas the participating university was labeled " $U$ ". Meanwhile, the number code was based on the alphabetized name of the participating university and the number after a dash indicates their cardinal number.

\subsection{Instrument(s)}

The instrument used in the data collection was an audio/video recorder. The techniques used were note taking, recording, and observation. Observation is important because it captures information that cannot be secured by recorders and it enables us to understand the whole context of the communicative event (Querol-Julian, 2010).

The actual conduct of colloquium was recorded using three electronic gadgets: digital voice recorder, audio/video recorder (Sony HDR-PJ230 Digital HD Video Camera Recorder), and a cellular phone (Samsung GT-S7562) for back-up purposes.

We employed non-participant observation. Hence, we just served as merely observers during the colloquium and did not interact with the graduate students and panelists. We also used field notes to remember what we observed. We prepared an outline of the information to be included in our notes like the time frame of the colloquium and the arrival of the participants. It is worth noting here that the advisers and the panelists were asked some information like their length of service, academic rank, and year/s of experience as an adviser or as a panellist. These pieces of information would be helpful in interpreting some data in the study since IS having an interpretive nature, would need background information about the participants in order to understand some of their utterances in the colloquium.

\subsection{Data collection procedures}

Data collection started upon the completion of the consent documents. The verification of colloquium schedule lengthened our time frame allotted for data gathering because of the following: (a) difficulty in getting a definite schedule of colloquium (it could not be identified ahead of time because it depends on the student's submission of proposal) hence, we had to monitor the status of the schedule from time to time; (b) postponement of scheduled colloquium because of the unavailability of some panel members; and (c) incidence of conflicting schedules of observation when two participating universities had the same time of colloquium.

Observation and recording came next which lasted for a month. After this procedure, transcription followed. The help of some trusted colleagues was sought to roughly transcribe (no notation included) the recordings. The data were then analyzed and interpreted. After the initial analysis and interpretation, some of the participants were interviewed regarding their seating arrangement and forms of address used to validate the interpretation made.

\subsection{Data analysis}

This study used six hours, 17 minutes, and 57 seconds talk-time data recorded from the seven graduate students' colloquium. This is equivalent to 58,071 words (this figure was based on MS word count). 
This talk-time data was sufficient to identify the discourse structure of colloquium. As Gordon (2011) and Cameron (2001) point out, there is no specific number of participants and length of data required in discourse analysis. In fact, Limberg (2007) used seven minutes and 20 seconds as data; Waring (2002) had one and a half hour; Querol-Julian (2010) had two hours and ten minutes.

In analyzing the discourse structure of the colloquium, van Dijk's (1980) concept of semantic and schematic superstructure was used. The method of analysis followed Gonong's (2007) procedure where the data are labelled and grouped by functional categories. Specifically, the following were undertaken:

\section{A. Semantic Macrostructure}

1. Read the whole transcripts several times and segment them according to topic.

2. Get the initial macropropositions of the transcripts then delimit them into higher level macropropositions. This was done by translating the utterances into meaningful sentences then applying the macrorules (as discussed earlier), i.e., delete the irrelevant utterances.

3. Infer the semantic macrostructure based on the higher level macropropositions.

\section{B. Schematic Superstructure}

1. Read the whole transcripts several times.

2. Code the data. In this step, it followed Gonong's (2007) procedure where the data are labeled and grouped by functional categories. In assigning functions, the specific contribution of the sentence to the discourse or its function in the discourse such as whether it tells about the purpose of the colloquium or introduces the participants was identified first. Then, the sentences were grouped based on one identifiable broader functional category, i.e. introduction, presentation. Apart from these functions, we also identified several factors to border these categories: (1) Involvement of the participants. It is argued here that a change in participants indicates the boundary of the structure; and (2) Lexical cues. Lexical cues were another predictor of the part. These belong to surface cues (van Dijk, 1980). The examples of these cues were "will be asking you some clarifications", "will be criticized on later", and "okay, let's start with the questions". These signals were called the contextual knowledge and surface cues of van Dijk (1980).

\section{Results and Discussion}

\subsection{The semantic macrostructure of the colloquium}

Table 1 below reflects the semantic macrostructure of the seven colloquia observed and analysed.

Table 1. The semantic macrostructure of each of the colloquia

\begin{tabular}{cl}
\hline Participants & \multicolumn{1}{c}{ Semantic Macrostructure } \\
\hline U1 & Noting the absence of important details in the proposal \\
U2-2 & Intolerance of plagiarism \\
U3-1 & $\begin{array}{l}\text { Correcting the parts of the proposal that the panel disagreed with } \\
\text { Identification of the weaknesses of the proposal }\end{array}$ \\
U4-2 & $\begin{array}{l}\text { Identification of the weaknesses of the proposal } \\
\text { Clarification of the ambiguous and sketchy details in the } \\
\text { proposal } \\
\text { Guiding the graduate student on the proper construction and } \\
\text { presentation of her proposal }\end{array}$ \\
\hline
\end{tabular}


The apparent theme of $\mathrm{U} 1$ in Table 1 was noting the absence of the important details in the proposal wherein the panelists focused on the identified missing details in the proposal and requested the graduate student (GS) to elaborate them as revealed in line 4 of (1):

(1) 1 P2: $\quad$ lno need to indicate[ ((shakes her head))//

2 ]although you will discuss that //

3 in chapter 3.//okay.//okay,//no 2 is_//how will you_// how will this be answered//by your respondents< $<$ question $>/ /$ I_/ ano,/I'm

This theme could lead to an inference that in a proposal defense, the panelists are set to let the GS discover the weak points in her study through a series of questions and not to merely tell the latter what to do or what was missed in the study.

In U2-1 the inferred semantic macrostructure was the intolerance of plagiarism. The exchanges of utterances between the chair of the panelists and the GS had centered on the issue of originality. The transcripts (2), through many stressed words (in capital) and a lengthened vowel (line 3), manifested the chair's strong dislike of dishonesty. In this instance, the Filipino's communication style of indirectness was not apparent. It could be inferred therefore that valuing honesty and professionalism would reign over indirectness.

U2-1 (2) 1 okay_//so those are proofs that you are not honest_in writing your

2 paper.//We will not let that get THROUGH this panel. We will

3 not//LET a:ny_element of dishonesty in writing the paper//

This theme suggests that the panelists are not only mindful of the proposal itself but also of how it is written and that the colloquium serves right the GS who is prepared and able to follow scholarly academic writing. The act of the chair likewise reveals the fact that institutions of higher learning aim to produce moral and upright professionals (Resurreccion, 2012) and expresses his rights as a faculty to correct the student. Meanwhile, U2-2's revealed correcting the parts of the proposal that the panelists disagreed with as its semantic macrostructure. The interaction of the participants in U2-2 progressed through the correction of the parts of the proposal that the adviser and the panelists disagreed with thus revealing the theme presented above. This is apparent in the transcripts below:

U2-2 (3) 1 A:what are practices in listening and_//reading classroom activities in the

2 locale of the study<question>//if you will be able to_//ahh,//describe//

3 a-and_//analyze//the listening and reading_//classroom practices//

4 in the locale of the study_//I think that would be fine_((D nods))//

5 instead of just saying_//how do subject teachers use their students 11_//

In (3), the question of $A$ in lines 1-2 indicated his disagreement with the procedure of the GS and at the same time gave GS a hint on how to make her procedure more appropriate. In lines 4-5, this intention was finally revealed as reflected in his phrase "instead of just saying". This construction of commenting on the paper discloses another manner of helping the GS to improve her paper: ask a rhetorical question then give a suggestion. In this instance, A did not look into the deficiency but into the appropriacy of the paper. This style seems to be effective as it received a nod from GS, the hearer. With U3-1 and U3-2, the colloquia, which happened in the same university and with the same set of adviser and panelists, had a similar semantic macrostructure, the identification of the weaknesses of the proposal, as manifested below: 
U3 (4) $1 \quad \mathrm{P} 1$ : so//regarding//the content of your introduction, //ahh, //((..))//

$-1 \quad 2$ actually//you did not DWEll//on the management_//

3 because your topic is about_//self-efficacy, //practices,[//

4

]challenges//

5 as well as managing instructions_//but you just discuss lsupervision.

Sentence (4) evidently expresses that P1 directly informed GS on the part that she missed on her paper. Her directness was reflected in her emphatic delivery of "dwell". This utterance likewise implies P1's orientation towards the defense and to the GS, that is, that a panelist is there to help the GS improve her study by identifying the weakness of her paper and that the GS's work is there to be scrutinized.

Seeing from a different perspective, this reveals a teaching method, the so-called spoon-feeding or teacher-centered (Payongayong, 2007) where a teacher, the person in authority, gives what the student needs. As seen in (5), P1 did not encourage GS to think of the weakness of her paper but went directly at pointing it down. Similarly, the word "failed" in line 5 and the word "anak" in line 2 strengthened the view of P1 towards GS.

(5) 1 P1: yung_//regarding yung objectives.//so_//look at your paradigm

2 anak.//dependent variable, $[/ /$

3

4 GS: yes Ma'am//

5 P1: so_//you failed to://ahh,//define operationally//personal

6 characteristics,//wala rito,//and then professional characteristics//

$7 \quad(().) / /$ and the_//you only have two variable//

Meanwhile, U4-1 had the clarification of the ambiguous and sketchy details in the proposal. The utterances below reveal how the interaction proceeded with this theme:

U4-1 (6) 1 I'd like to be clarified with the //the major concern of your_//ahh,//

2 dissertation,//ahh,//am I right//if I say that you would be//

3 identifying best reading practices//of teachers module writers_//

4 and these_//ahh,//best practices //would serve as input //to//

5 the reading program $/ /$

It can be seen from (6) that some details in the proposal were presented vaguely. The panelist's utterances allowed GS not to feel that what she had written was incorrect. The phrases "clarified" (line 1) and "am I right" (line 2) suggest that something had only been missed out and that the panelist had just misunderstood the point in her paper. This clarification could be inferred as a hint, too, for GS to be clarified with her paper because of the phrase in lines 4-5, "and these best practices would serve as input to the reading program".

The last colloquium, U4-2, revealed this semantic macrostructure, guiding the graduate student on the proper construction and presentation of her proposal as what could be inferred from the utterances below:

U4-2 (7) 1 P1: what professor NAME is telling you_//is_//

2 there has to be some kind of NEEDS assessment.//

(8) 1 P1: instead of dd-DDe.//This is dde.//Yong addie, // 
2 you can modify it_/let's say analysis,//then design,//

3 development, ((P3 and A write) $) / /$ implement//evaluate.

The panelists expressed their ideas and/or suggestions in an unoffensive and sympathetic manner which sounded like a guidance as evident in lines 1 (7) and 2 (8). This gives an impression that a colloquium is a potent venue to strengthen the parts that are seen to be weak and that the panelists are there to help serve this purpose. This inference contradicts the reported perception of the individuals in Tannen's (2002) study that a defense has an agonistic nature and that the panelists are likened to a "den of wolves."

The last theme also reflects that a colloquium may take different meanings depending on how the participants construct them. As Potter, Wetherell, Gill, and Edwards (1990) put, what is picked out in talk depends on the orientation and interests of the speaker.

In summary, although the individual semantic macrostructure showed a theme of its own, through a generalization process (van Dijk, 1980), the common semantic macrostructure of the colloquia was "the ironing out of the observed weaknesses and deficiencies of the presented proposal." It is argued that while the panelists might have taken different styles of expressions which could shape the theme of the interaction, this would leave an apparent general semantic macrostructure, formed by one's academic culture and institutional conventions.

\subsection{The schematic superstructure of a colloquium}

The identified superstructure of a colloquium was composed of three parts labeled as (a) pre-defense, (b) defense proper, and (c) post-defense. The naming of the parts was possible because as van Dijk (1980) puts it, the hearer or reader has plausible expectation about the type of discourse and that he/she has previous assumption about the schematic structure of the text.

In U1, the schematic superstructure followed eight categories under the pre-defense part. As shown in Figure 1, the categories greetings, introduction, and prayer preluded the presentation of the proposal. The occurrence of greetings is a protocol in an interaction (Duranti, 1997; Rydblom, 2014). It is an important ingredient for it is a form of maintaining social relationship and an indication of politeness (Wei, 2010) and solidarity and respect (Grimshaw, 1980 in Rydblom, 2014; Torres \& Medriano, 2020). The inclusion of prayer, on the other hand, is a customary practice in U1 being a Catholic university.

The defense proper which shaped the attainment of the colloquium's collective goal, had 11 categories. Among these parts, only the data gathering procedure, instruments, review of related literature (RRL), and references were given close attention by the panelists. The last part, included six categories where two turns of thanking, one by the chair/dean and one by the GS, concluded the colloquium. In U2-1, only four categories were identified in the pre-defense part, two in the defense proper part, and five in the post-defense. 


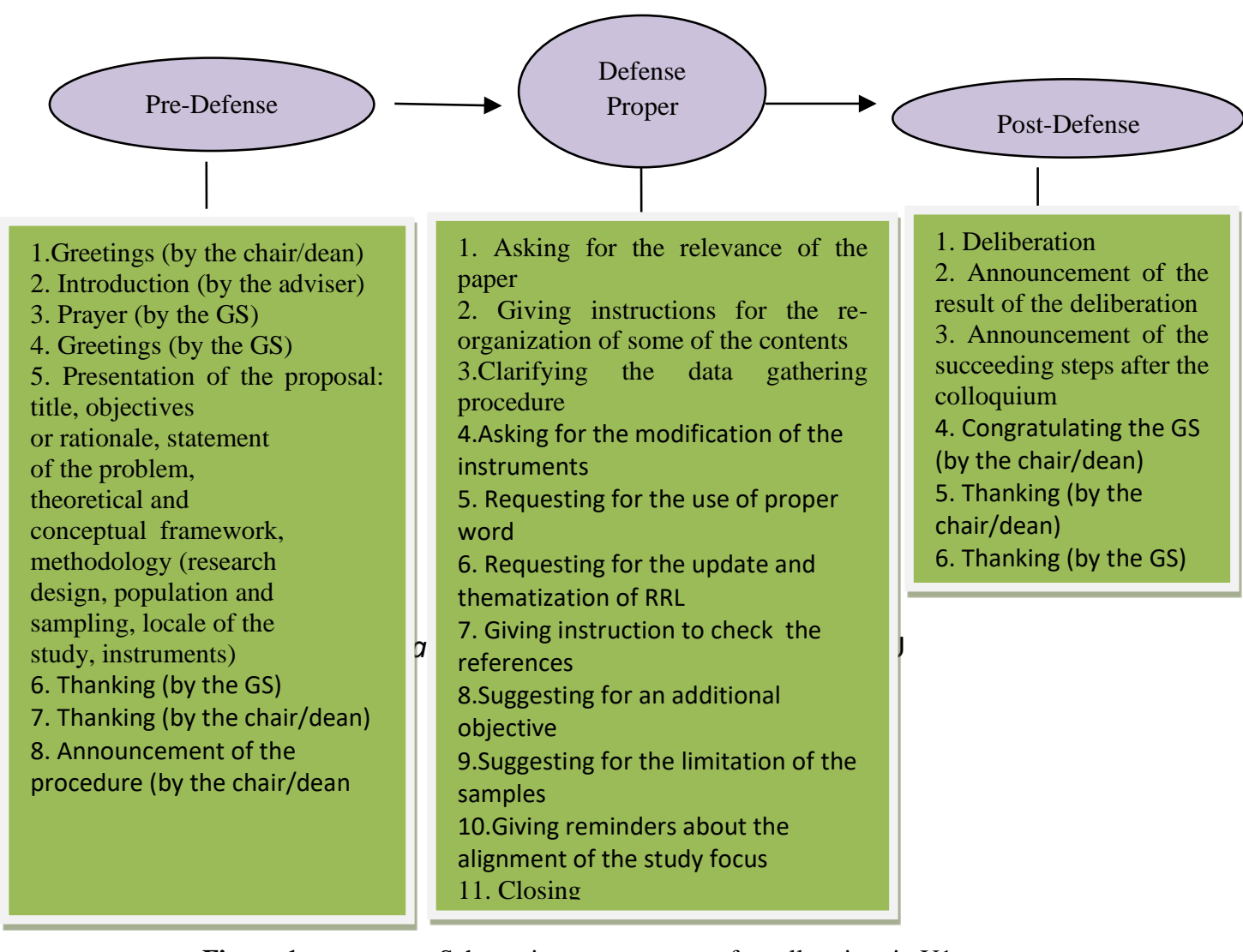

Figure 1.

Schematic superstructure of a colloquium in U1

In contrast, U2-1 (Figure 2) started with an introduction of the panelists by the chair/dean followed by a greeting, a self-introduction of the GS, and the presentation of the proposal. It is worth mentioning here that the GS in U2-1 was the second in the group of the presenters on that day. This could attribute to the absence of greetings by the chair/dean, that is, it is assumed that this category could have been present during the first GS's proposal presentation

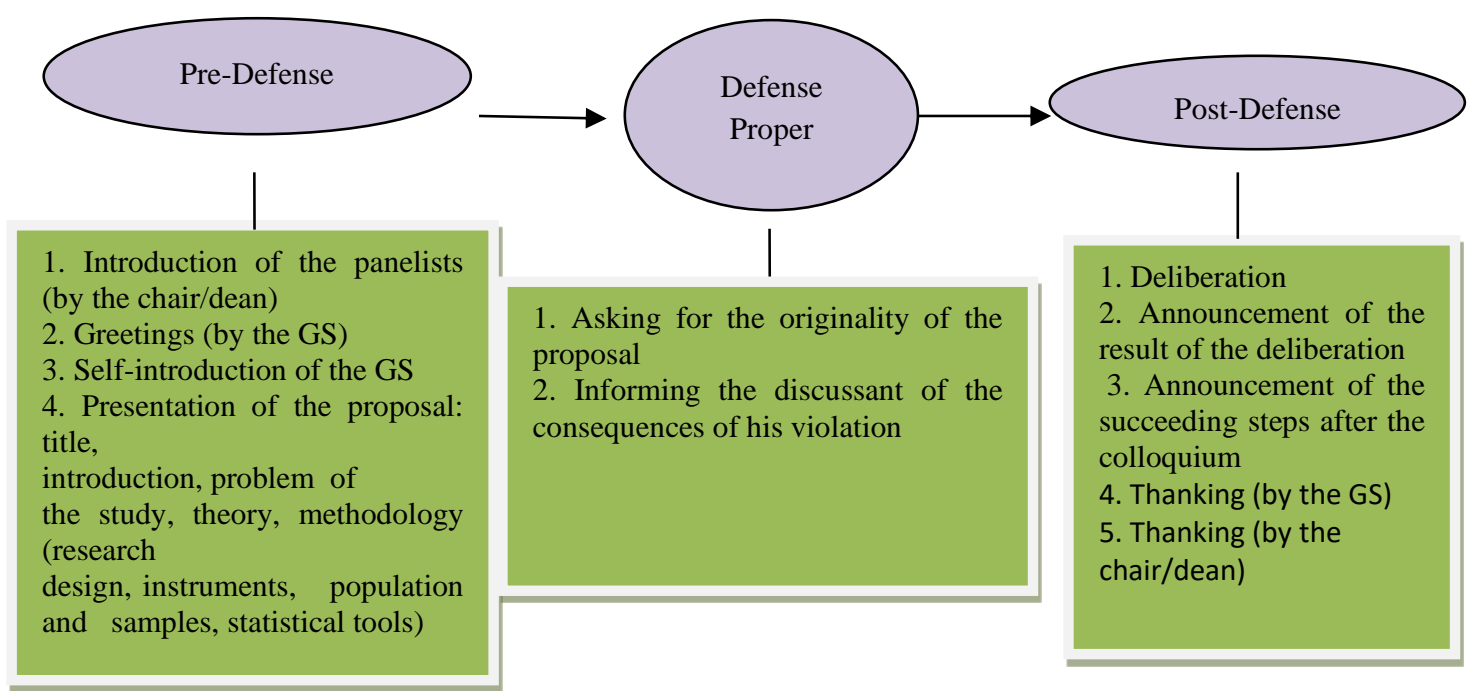

Figure 2. Schematic superstructure of a colloquium in U2 
Figure 2 reflects that the two categories in the defense proper part were the asking for the originality of the paragraphs in the proposal and informing the GS of the consequences of his action. This situation prompted the post-defense part to include deliberation in its categories. The deliberation in U2-1 was different in purpose from $\mathrm{U} 1$ because in the former, it aimed to deliberate what course of action should be given to the violation committed by the graduate student, not on the result of the evaluation of the proposal. Nevertheless, post-defense concluded with the category thanking.

In U2-2, the same categories with U2-1's pre-defense were observed as revealed in Figure 3. Figure 3 illustrates that the defense proper part consisted of ten different categories. As regards the post-defense part, a wish of good luck by the chair/dean and gratitude by the GS were the identified categories.

Generally, this figure reflects that deliberation is not a traditional category in $\mathrm{U} 2$ and that it is situationdependent. This inference was made because in U2-2, this category was absent in the post-defense part. It is noted that the graduate students in U2-1 and U2-2 came from the same university.

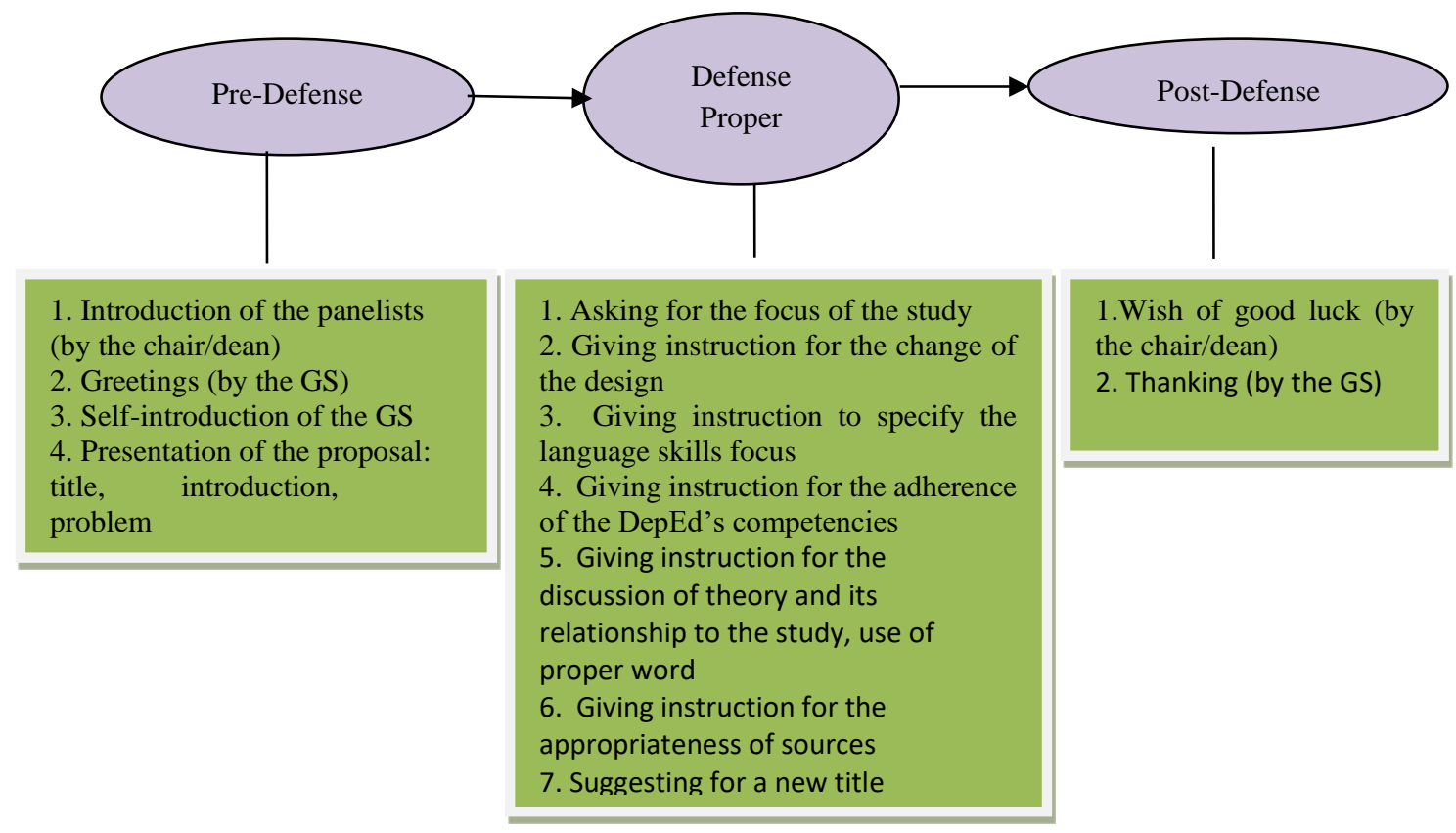

Figure 3. The Schematic Superstructure of U2-2

As regards the schematic superstructure of U3-1 (Figure 4), six categories were identified in the predefense, five in the defense proper, and three in the post-defense part. Figure 4 further reflects that like U1, the first category was a greeting done by the chair/adviser and the category "announcement of the chair/adviser about the next steps after the colloquium" was included in the post-defense part, and that "thanking" both by the chair/adviser and the GS was the final category. 


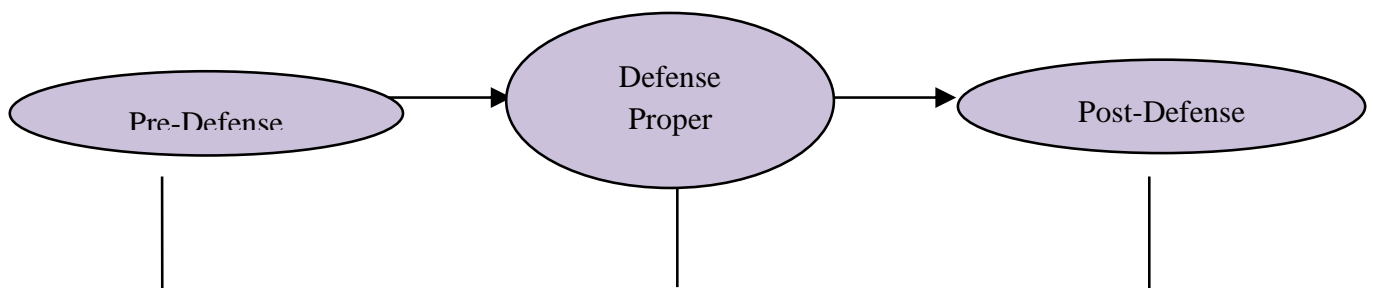

1. Greetings (by the chair/adviser) 2. Introduction (by the moderator/adviser)

3. Prayer

4. Greetings (by the GS)

5. Self-introduction of the GS

6. Presentation of the proposal: title,

introduction, objectives, significance, methodology (theoretical and conceptual paradigm, respondents, research design, instrumentation, pretesting of instruments, method of data gathering, method of analysis)
1. Instructing the GS to recast the introduction of the statement of the problem

2. Giving instruction to update the RRL and provide a summary of it

3. Giving instruction to improve the definition of terms and referencing

4. Giving instruction for the congruency of parts

5. Closing
1. Announcement of the succeeding steps after the colloquium

2. Thanking (by the chair/adviser)

3. Thanking (by the GS)

Figure 4. The Schematic Superstructure of U3-1

The data from Figure 4 differ from those in Figure 5 showing the schematic superstructure of U3-2.

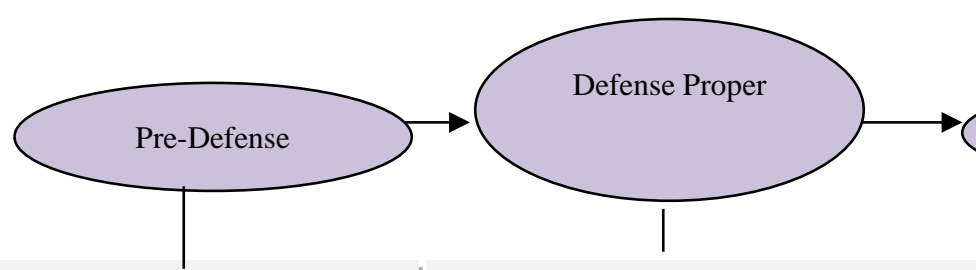

1. Greetings (by the chair/adviser)

2. Introduction (by the chair/adviser)

3. Greetings (by the GS)

4. Self-introduction of the GS

5. Presentation of the proposal: title, introduction, SOP, objectives, hypothesis, significance, scope and delimitation, methodology (theoretical and conceptual framework, design, locale, sample and sampling procedure instruments, data gathering procedure, methods of data analysis statistical treatment)

6. Thanking (by the chair/adviser)

7. Announcement of the procedure (by the chair/adviser
1. Instructing GS to check the title

2. Instructing GS to organize the content

3. Asking for the gap

4. Asking GS to modify the instruments

5. Requesting for the proper word choice, update of RRL, and inclusion of local studies and summary

6. Giving instruction for proper referencing

7. Giving instruction for the modification of objective

8. Instructing $D$ to observe congruency of parts

9. Instructing GS to modify the definition of terms procedure and on the instruments 11. Instructing GS to review the statistical treatment and the format 12. Closing
10. Asking GS to be explicit on the

Figure 5. The Schematic Superstructure of U3-2 
In U3-2, the category "prayer" in the pre-defense part was omitted. This could be due to the order of presentation where the GS in U3-2 was the second presenter for the day. Further, the same participants were present in the colloquium. Another significant difference observed as revealed by the categories was the inclusion of "announcement of the procedure." This category was absent in U3-1. It could be inferred therefore that the categories were shaped by the number of the graduate students in a day and by the rule of interaction.

As for the defense proper part, twelve categories were identified. The closing category was both observed in U3-1 and U3-2. In the post-defense, three categories emerged- congratulating the GS, thanking the participants by the chair/adviser, and expressing wishes for the GS. Meanwhile, the schematic superstructure of U4-1 had six categories under pre-defense, ten in the defense proper, and three in the post-defense. Greetings and introduction preluded the presentation and the announcement of the procedure category ended it. The categories on the defense proper focused on the major concern of the study, framework, data gathering procedure, RRL, organization of content, and formulation of a new title. Like U3-1 and U3-2, U4-1 had no deliberation category in its post-defense. This implies that deliberation is not a part of the colloquium in these universities. Instead announcement and thanking were the only categories identified. The schematic superstructure of U4-1 is concretely illustrated in the Figure 6.

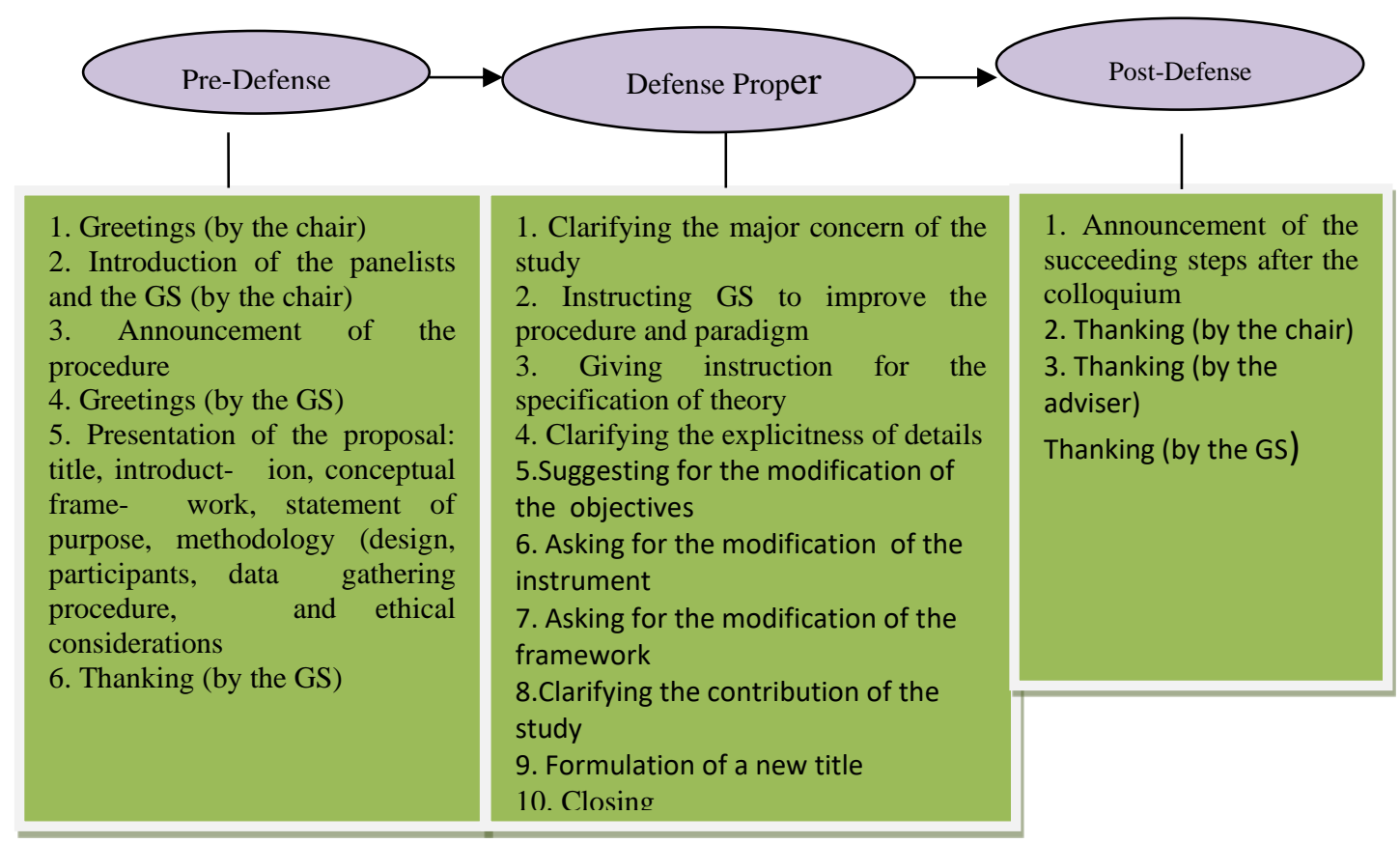

Figure 6. The Schematic Superstructure of U4-1 
Turning now to U4-2, seven categories were identified in its pre-defense part (Figure 7).

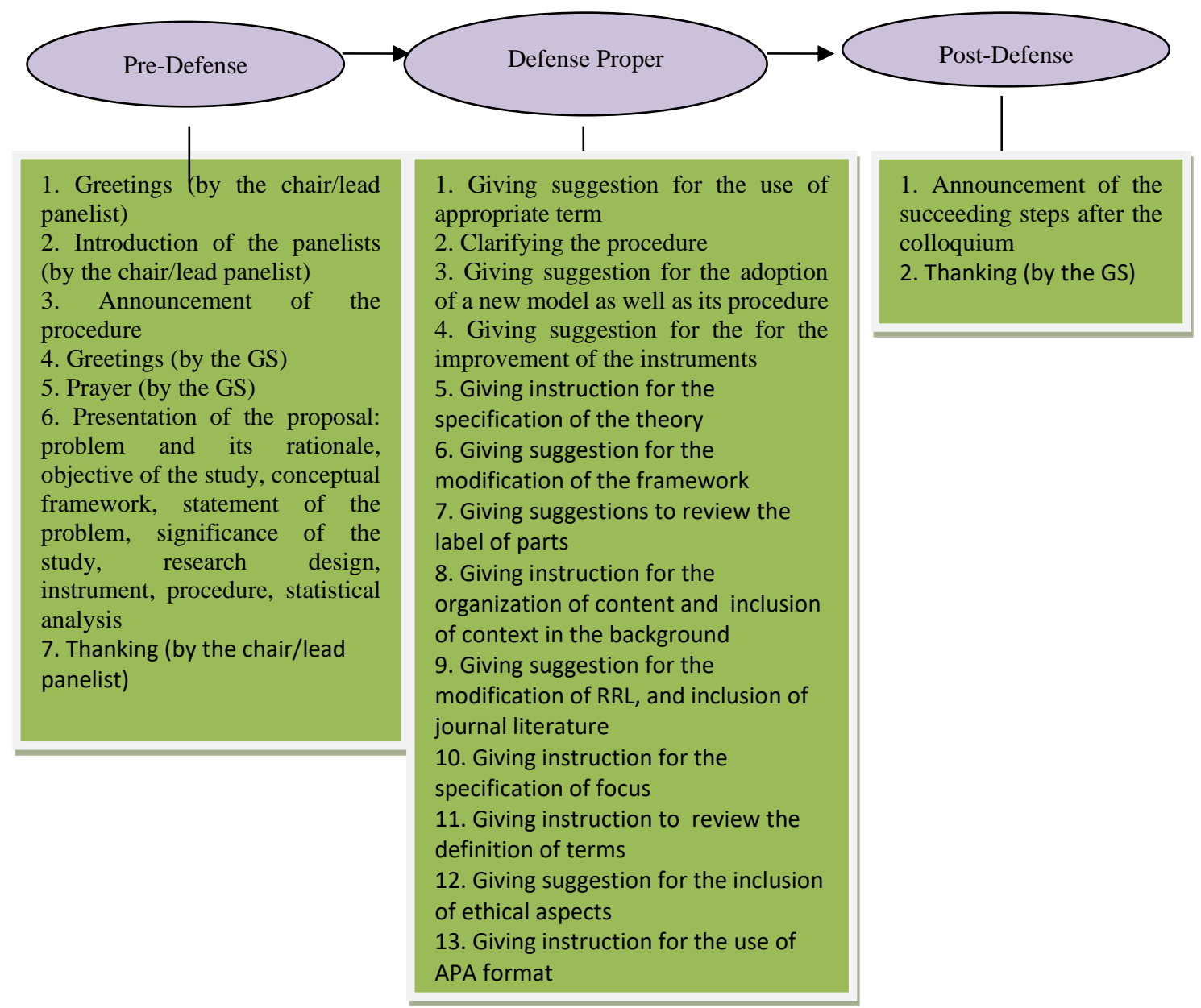

Figure 7. The Schematic Superstructure of U4-2

Meanwhile, 14 categories were identified in the defense proper part and two in the post-defense part. Unlike U4-1, this structure did not include the modification of title category; instead, the model used by the study was modified.

Figure 8 sums up the schematic superstructure of the seven colloquia where eight categories were identified in the pre-defense part. Three recurrent categories among the seven colloquia were identified- the introduction by the adviser, greetings by the GS, and the presentation of the proposal. The rest of the categories such as the greetings by the chair, prayer, thanking by the GS and by the chair, and the announcement of the procedure were found to be optional (indicated by an open and close parentheses). It was mentioned that some factors affected the categories in the pre-defense like the number of the graduate students presenting within the day, the presence of the same participants in the colloquium, and the violation of the rules of interaction.

As for the defense proper, it consisted of three categories, two recurring and one optional. The figure also displayed that except for the modification of the content, the panelists had different concerns relevant to the parts of the proposal such as the data gathering procedure (explicitness), instruments (appropriateness, additional), references (proper citation), review of related literature (update, thematization, additional), framework (congruency with the objectives), objectives (appropriateness), definition of terms (correctness), statistical tools (appropriateness), format (appropriateness), title (appropriateness), design (appropriateness), participants (limitation), and model (appropriateness). 
Other parts such as the gap, theory, and focus were asked to be specified as well as the ethical considerations.

The defense proper was reflective of the assertion of Celce-Murcia and Larsen-Freeman (2008) that there are various kinds of linguistic realization for one certain intention. It could be done by asking the GS to elaborate the less explicit details or pinpointing to him/her the weak points of his/her proposal. Further, it is argued that the differences in linguistic realization might be attributed to the participants' style of expression, academic culture and institutional conventions, social distance, and power relation.

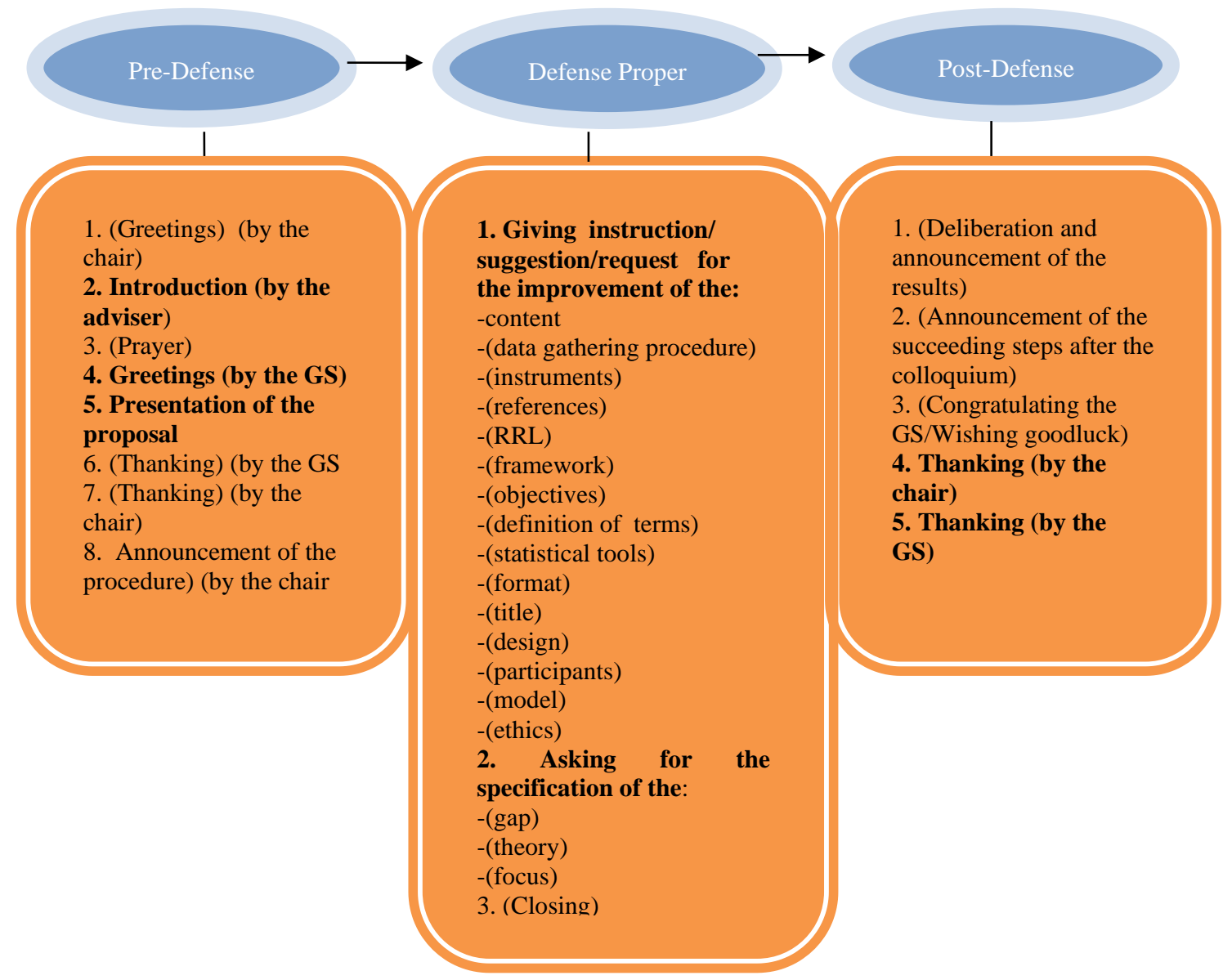

Figure 8. The Schematic Superstructure of a Colloquium

The last part was the post-defense which included five categories, three optional and two consistent categories. These categories were the deliberation and announcement of its results (optional), announcement of the succeeding steps after the colloquium, congratulating the GS/ wishing of goodluck (optional), thanking by the chair, and thanking by the GS.

The schematic superstructure of the colloquium conveys the collective goal of this academic event specifically the defense part in which the panelists give instructions, suggestions, and requests to improve the organizational content and the parts of the paper. In addition, the schematic superstructure reflects the Filipino trait of being thankful or appreciative (Dancel, 2005; Andres, 1996) as evident on the GS and the chair thanking the panelists for listening and commenting on the paper, and for coming 
to the colloquium. This gesture is one of the means how Filipinos maintain smooth personal relation (Lynch, 1962 in Reyes, 2015; Torres, Balasa, Ricohermoso \& Alieto, 2020) with one another.

In addition to this, the schematic superstructure exhibits the respect between and among the participants in conducting the colloquium. During the pre-defense part, only the chair, the adviser, and the GS had roles to perform. The other participants, the panelists, waited for the chair to signal their participation. Each of the participants acknowledged the role of the chair in administering the proceedings of the colloquium. This acknowledgement of the chair displays how the Filipinos give importance to hierarchy of responsibility. Filipinos who are family oriented (Ramirez, 1991 in Claridad, 2006) recognize leadership and give respect to the assigned leader of the group.

\section{Conclusions}

Based on the findings of this study, it is concluded that the semantic macrostructure of a colloquium is reflective of its collective goal which is attained through the interactions of the participants and that its schematic superstructure is always followed in realizing the collaborative end of the colloquium. Each phase consists of both obligatory and optional features that define/reflect the institution's identity and practice. The findings of this research imply that the success of graduate students in passing their academic colloquium requirement can be attributed to their knowledge of the proceedings in such an event and manifest a need for an inclusion of a moderator whose focus is on guiding the flow of the discussion and summarizing the points afterwards to help achieve the goal of the colloquium.

How can graduate students benefit from the findings above? One specific benefit would be that the presenters will have an idea on how the process is carried out. As Morita (2000 in Tan, Polong, Collantes \& Torres, 2020) opined, academic discussions (e.g., colloquium) when carefully designed and properly done can be a potent method in fostering interactive communication among students as they bring forth an array of knowledge and experiences that are shared and built upon by the participants (e.g., graduate students, panelists) in a conducive learning environment where passiveness is turned to activeness. Although it is well understood that different universities employ different procedures, establishing a universal structure founded on concrete observations from different universities can provide a perspective for aspiring presenters and graduates so they will not charge ahead empty handed. Having an idea of the colloquium structure, the presenters can now establish small, achievable goals per part of the colloquium. Moreover, understanding the different segments, they have an idea if they are achieving their set goals with the goals of the actual presentation. This study can work like a springboard, a map, and a survival guide, towards a graduate student's success in a colloquium.

Writing guides for research work have always been vague and shots for a "one-size-fits-all" effect. If students are already aware of what waits for them, they can prepare for it ahead of time. They can write in style that fits the taste of the panel or the university, since the structure discovered in this study clearly establishes majority of what needs to be written in certain parts of a research work. On top of that, this study also drew inferences of what the panelist general attitude is towards content and writing style of colloquium presenters.

\section{ACKNOWLEDGMENTS}

Completing this research endeavor would not have been possible without Dr. Cecilia Mendiola, Dr. Florencia Marquez, and Dr. Philip Jay Alcoberes who have been so generous in sharing their expertise on how to improve the entirety of this undertaking. We are also indebted to the people who worked on 
the technical side, our layout editor, Mr. Kevin Ray Abesamis, and our language editors, Ms. Caroline Dacwag and Dr. Myla L. Santos.

The graduate students, their panel members, and their respective institutions who graciously lent their invaluable time and support to gather the data needed in this study is also noteworthy of acknowledgment. Lastly, to the people who tirelessly provided our hearts with motivation and spirit, our family, we give our utmost gratefulness.

\section{References}

[1] Alcoberes, P. J. N. (2010). The rhetoric of travel advisory: A critical discourse analysis (Unpublished doctoral dissertation). Philippine Normal University, Manila, Philippines.

[2] Andeweg, B. A., de Jong, J. C., \&Hoeken, H. (1998). May I have your attention?: Exordial techniques in informative oral presentations. Retrieved from http://www.tbm.tudelft.nl/fileadmin/Faculteit/TBM/Over_de_Faculteit/Afdelingen/Stafafdelingen/Instituu t_voor_

[3] Andres, T. (1996). Effective discipline through Filipino values. Philippines: Rex Book Store Inc.

[4] Arriff, T. \& Mugableh, A. (2013). Jordanians' academic discourse socialization through oral academic presentations in Malaysia. International Journal of Linguistics and Communication, 1(2). Retrieved from http://aripd.org/journals/ijlc/Vol_1_No_2_December_2013/1.pdf

[5] Bamford, J. (2000). Question and answer sequencing in academic lectures. In M. Coulthard, J. Cotterill, \& F. Rock (Eds.), Dialogue analysis VII: Working with dialogue. Proceedings of the $7^{\text {th }}$ IADA Conference Birmingham 1999 (pp.159-69).Tübingen: Max Niemeyer.

[6] Barron, A (2003). Acquisition in Interlanguage Pragmatics: Learning How to do Things With Words in a Study Abroad Context. John Benjamins.

[7] Celce-Murcia, M.\& Larsen-Freeman, D. (2008). The grammar book: An ESL/EFL teacher's course (2nd ed.). Boston, Ma: Heinle \& Heinle.

[8]Chen, S. (2012). Making sense of the public PhD dissertation defense: A Qualitative multi-case study of education students' experiences. Retrieved from http://www.collectionscanada.gc.ca/obj/thesescanada/vol2/QMM/TC- QMM-114288.pdf

[9] Claridad, G. (2006). Mediation among Filipinos: Indigenizing the methods of mediation into the Philippine context. Retrieved from http://www.asiapacificmediationforum.org/resources/2006/claridad.pdf

[10] Csongor, A. (2013). Rhetorical moves and hedging in medical research articles and their online popularizations. Retrieved from http://lstp.etk.pte.hu/portal/wp/File/Doktoriiskola/Tezisfuzetek/CsongorA_dizzi.pdf

[11] Dancel, F. (2005). Utang na Loob (Debt of Goodwill): A philosophical analysis. In R. M. Gripaldo (Ed.), Filipino cultural traits: Claro R. Ceniza Lectures (pp. 109-128). USA: The Council for Research in Values and Philosophy.

[12] Duff, P. A. (2010). Language socialization into academic discourse communities. Annual Review of Applied Linguistics, 30, 169-192.doi:10.1017/S0267190510000048.

[13] Duranti, A. (1997). Polyphonic discourse: Overlapping in Samoa ceremonial greetings. Retrieved from www.sscnet.ucla.edu/anthro/faculty/duranti/reprints/polyphonic.pdf 
[14] El Sakran, T., \& Adamson, J. (2019). A Genre Analysis of the Schematic Structure and Linguistic Features of Reviewers' Reports on Research Manuscripts. Asian ESP Journal, 15(3), 7-55.

[15] Fairclough, N. (2003) Analysing Discourse: Textual analysis for social research. New York: Routledge.

[16] Gee, J.P. (1999). An Introduction to Discourse Analysis: Theory and Method. New York: Routledge

[17] Gochuico, J. V., Gonong, G. O., \& Reyes, Z. Q. (2015). Power and ideology in the Catholic Bishops' Conference of the Philippines' pastoral letters after the Martial Law years: A critical discourse analysis. The Normal Lights: Journal on Teacher Education, 9 (1), 49-71.

[18] Gonong, G. O. (2007). Image construction of a developing nation in presidential rhetoric: a critical discourse analysis. (Unpublished doctoral dissertation). Philippine Normal University, Manila, Philippines.

[19] Gordon, C. (2011). Conversation and interaction. In R. Mesthrie (Ed.), The Cambridge handbook of sociolinguistics(pp.105-121). United States of America: Cambridge University Press.

[20] Limberg, H. (2007). Discourse structure of academic talk in university office hour interactions. Discourse Studies, 9(2), 176-193. doi:10.1177/1461445607075343.

[21] Maingueneau, D. (2002). Analysis of an academic genre. Discourse Studies, 4, 319-341. doi: $0.1177 / 14614456020040030401$.

[22] Matsuoka, R. (n.d). An analysis of the oral academic discourse in discussions.Proceedings of the 8TH Conference of Pan-Pacific Association of Applied Linguistics, 235-246. Retrieved from http://www.paaljapan.org/resources/documents.html

[23] Payongayong, MT. (2007). Creating a community of inquiry through philosophy. Trans. Natl. Acad. Sci. and Tech. Philippines, 29, 306-310. ISSN: 0115-8848

[24] Potter, J., Wethrell, M., Gill, R., \& Edwards, D. (1990). Discourse: Noun, verb or social practice? Philosophical Psychology, 3 (2-3), 205-217. DOI: 10.1080/09515089008572999

[25] Querol-Julian, M. (2010). Multimodality in discussion sessions: Corpus compilation and pedagogical use. Language Value, 2(1), 1-26. Retrieved from http://www.erevistes.uji.es/languagevalue

[26] Recski, L. (2005). Interpersonal engagement in academic spoken discourse: A functional account of dissertation defenses. English for Specific Purposes, 24, 5-23. Retrieved from www.elsevier.com/locate/esp

[27] Resurreccion, P. (2012). The impact of faculty, peers, and integrity culture in the academe on academia misconduct among Filipino students: An empirical study based on social cognitive theory. International Journal of Academic Research in Business and Social Sciences, 2 (12). ISSN: 2222-6990.

[28] Reyes, J. (2015). Loób and kapwa: An introduction to a Filipino virtue ethics. Asian Philosophy, 2 (2), 148-171. doi: 10.1080/09552367.2015.1043173

[29] [29] Rydblom, O. (2014). You still say hello! A corpus study of the greeting words hi, hey and hello in spoken American English. Retrieved from https://www portal.org/smash/get/diva2:713676/FULLTEXT01.p 
[30] Seidlhofer, B. (1995). Approaches to Summarization: Discourse Analysis and Language Education. Tübingen:Narr

[31] Swales, J. (1990). Genre analysis: English in academic and research settings. UK: Cambridge University

[32] Tan, R.K., Polong, R.B., Collantes, L.M., \& Torres, J.M. (2020). Influence of small group discussion on the English oral communication self-efficacy of Filipino ESL learners in Central Luzon. TESOL International Journal, 15(1).

[33] Tannen, D. (2002). Agonism in academic discourse.Journal of Pragmatics, 34, 1651-1669.

[34] Torres, J.M. (2020). Politeness strategies vis-à-vis genders and exposures to western culture: The case of the 'The Voice of the Philippines' coaches. International Journal of Linguistics and Translation Studies, 1(3), 100-117.

[35] Torres, J.M., Balasa, K.A., Ricohermoso, C., \& Alieto, E.O. (2020). Complimenting strategies in sociolinguistic settings: The case of Ilocano and Tagalog pre-service teachers. The Asian ESP Journal, 16(5.1), 202-253.

[36] Torres, J.M., \& Medriano, R. (2020). Rhetorical Organization of Ilocano and Tagalog Pre-service teacher in their argumentative essays. The Asian EFL Journal, 27(2.2.), 261-286.

[37] Torres, J.M., \& Flores, E.R. (2017). Exploring the role of L2 in L1 writing: Clues from English teachers' think aloud protocols. Philippine Journal of Linguistics, 48, 30-50.

[38] Torres, J.M. (2013). Translating Teacher Cognition on Grammar to Classroom Teaching. Education Digest, 14, 1-18.

[39] Torres, J.M. (2012). Inventory of Language use in scholarly discourse. Education Digest, 13, 118.

[40] Tracy, K. (1997). Colloquium: Dilemmas of academic discourse. Norwood, NJ:Ablex.

[41] Tracy, K. \& Baratz, S. (1993). Intellectual discussion in the academy as situated discourse. Communication Monographs, 60(4), 300-320. doi:10.1080/036377593093763

[42] Van Dijk, T. A. (1988). News analysis. Case studies of international and national news in the press. Hillsdale, New Jersey, Hove and London: Lawrence Erlbaum Associates, Publishers. Retrievedfrom:http://www.discourses.org/OldBooks/Teun\%2520A\%2520van\%2520Dijk\%252 $\% 2520 \mathrm{News} \% 2520$ Analysis.p

[43] Van Dijk, T. A. (1980). Macrostructures: An interdisciplinary study of global structures in discourse, interaction, and cognition. Hillsdale, New Jersey: Lawrenc Erlbaum Associates, Publishing.

[44] Waring, H. (2002). Expressing Non-comprehension in a US Graduate Seminar. Journal of Pragmatics, 3,1711-1731. Retrieved from http://www.tc.columbia.edu/faculty/tesol/al/

[45] Wei, L. (2010). The functions and use of greetings. Canadian Social Science, 6 (4),56-62.

[46] Weissberg, B. (1993). The graduate seminar: Another research-process genre. English for Specific Purposes, 12, 23-35.

[47] Yang, W. (2014). Stance and engagement: A corpus-based analysis of academic spoken discourse across domains. LSP Journal, 5(1), 62-78. 
[48] Young, L. (1994,). University lectures-macro-structure and micro-features. In J. Flowerdew (Ed), Academic listening: Research perspectives (pp. 159-176). Cambridge: Cambridge University Press.

[49] Zamel, V. (1998). Questioning academic discourse.In V. Zamel \& R. Spack (Eds.). Negotiating academic literacies: Teaching and learning across languages and cultures (pp. 187-197). USA: Lawrence Erlbaum Associates, Publishers

[50] Zareva, A. (2015). I think I wanna talk about the reasons why I chose my topic: Discourse functions of self-mention in East Asian TESOL graduate student presentations. The Journal of ASIA TEFL, 12 (1), 141-168.

[51] Zareva, A. (2013). Self-mention and the projection of multiple identity roles in TESOL graduate student presentations: The influence of the written academic genres. English for Specific Purposes, 32, 72-8.

[52] Zareva, A. (2012). Lexical composition of effective L1 and L2 student academic presentations. Journal of Applied Linguistics, 6(1), 91-110.

[53] Zareva, A. (2011). And so that was it: Linking adverbials in student academic presentations. RELC Journal, 42 (1), 5-15. 